\title{
Building Resilience in Chronic Trauma through Self- Regulation
}

\author{
Hasna Abu Khalid, M.Ed. \\ University of Seattle, United States
}

Doi: 10.19044/ejes.s.v6a7

URL:http://dx.doi.org/10.19044/ejes.s.v6a7

\begin{abstract}
Self-regulation is a life skill that benefits human development in general and can support building of resilience with which to survive and thrive through experiences of trauma, especially when impact of trauma has a chronic nature. Academic study provides an experience that requires exercise of self-regulation to attain success much as the need to survive and thrive through trauma. Research has indicated role of student-driven factors such as self-regulation in academic performance. A study conducted with educators in training provided indication that educators are enriched to help students grow in self-regulation as the educators themselves practice facets of selfregulation The study examined self-regulation from selected scales of the MSLQ of Organization, Resource Management, Effort regulation, and HelpSeeking. Discussion of results provides implications for building resilience for support in trauma. Study results will assist educators in promotion of student self-regulation behaviors that can facilitate successful academic endeavor and habit formation of resilience practices. Answers will also provide guidance to educators and institutions on priority of effort in students support for selfregulation.
\end{abstract}

Keywords: Self-regulation, resilience building, educator interventions for trauma experiences.

\section{Introduction:}

Success in academia has long included capacity of students to engage in self-regulation as they manage time, prioritize daily activities, and devote energy and resources to course assignments. This endeavor of self-regulation can also support resilience of persons in the midst of trauma, especially chronic trauma such as life in poverty, the aftermath of living through a natural disaster or acts of violence on a person or group. Development of selfregulation capacity is a core component of P12 education. Swick, Knopf, Williams, and Fields (2013) noted that "children experience chronic stress in 
ways that can impair their brain functioning and overall development" (p. 181).

Ryan, Lane, and Powers (2017) described the foundational development of self-regulation with students in kindergarten. An example is the basic capacity to share space, resources, and even the attention of a teacher with other children, Ryan, et al. noted that as students matured in selfregulation skills through even use of these in play, they enhanced their internal neural plasticity and grew in capacity to adapt these skills to greater depths of functioning. This habit-building of self-regulation could provide benefit when faced with the challenges of trauma.

The adage of "Practice what one Teaches" dictates that educators and education support personnel practice effective self-regulation in their own lives in order to more effectively help their students to develop habits of beneficial self-regulation. Vermunt (2005) examined the role of selfregulation with undergraduate student learning and found that external regulation factors such as educator initiative promoted learning. Equally influential and even to some extent, more influential were the self-regulation processes such as "“"planning learning activities, monitoring progress, diagnosing problems, testing one's results, adjusting and reflecting” (p. 213).“

According to Jacobson and Harrison (2008) self-regulation activity with non-traditional students in a distance learning format offers even more pertinent focus on capacity to self-regulate in meeting needs or wants in the absence of much external regulation support as might be more present in a traditional learning environment. Jacobson and Harrison defined selfregulated learning as "a dimensional construct that contained the three aspects of cognition, individual motivation, and goal-directed behavior" (p. 414). Aspects of self-directed learning that could transfer to surving and thriving through trauma would be monitoring one's self, setting goals to meet needs, and adapting learned strategies to meet personal needs.

\section{Literature Review}

Literature review focused on the examination of self-regulation as promoted in work with children/students and relevant strategies for support of children/students as they experience chronic trauma. This review yielded indication that self-regulation is indeed a vital component of survival and thriving through chronic trauma. The review also provided evidence of educator integration of this as an important focus of developmental support with children/students

\section{Self-Regulation}

An example of professionals learning to practice what they preach and teach is with medical professionals such as doctors and nurses. Patients do 
look at how these people care for their own health in consideration of following prescribed health practices. Potgieter (2015) examined this pradigm and found that these professionals could support and encourage self-care by members of their public they served to the degree that they effectively cared for self. Potgieter also found that these health care practitioners in training experienced the same challenges in self regulation as did others in academic pursuit.

Self-regulation develops via the locus of control with an individual. Internal locus of control is represented in a personal belief of control over outcomes in various aspects of life, while external locus of control is represented in a personal belief that outcomes are beyond the personal control and due to factors outside personal management. Marr and Wilcox (2015) studied self-regulation with personal health and found that high internal locus of control was predictive of better health outcomes such as less practice of negative health habits and greater practice of positive health habits such as healthier dietary habits.

Self-regulation has been explored as a component of thriving and surviving through the chronic nature of complex trauma. Gilgun and Hirschey (2017) examined integration of self-regulation as a component of personal characteristics for clients of case management services in childhood complex trauma. Gilgun and Hirschey found that self-regulation was an important consideration for both the children and their families. They also found selfregulation to be a crucial component for the effectiveness of the case managers themselves.

In examination of the needs of children experiencing chronic stress and strategies, Swick, et al. (2013) found that both families and schools could employ to support development of these children across multiple life domains. As children are still developing the benefit of internal locus of control, this study supported vital benefit from external support for children in chronic stress/trauma. Swick, et al. explained that brain and other development occurs from life influences from the time of birth onward. As insult from trauma can adversely impact development, the role of family and school would be vital to promote provision of an environment where capacity for resilience could grow. Three needs were seen as prominence for support: (1) Need for safety; (2) Need for attachment; and (3) Need for consistency. These needs can be supported through physical set-up of environments, formation of habitual caring relationships, and employment of routine meaningful life structure.

\section{Educator Strategies of Support with Chronic Trauma}

Benefit is often derived from organizations such as schools looking to other organizational models. An example was a study by Overstreet and Mathews (2011) that examined use of a public health framework to help 
promote development of resilience with youth. Overstreet and Mathews noted that today's youth experience exposure to multiple and co-occuring trauma events, which can greatly predict life outcomes, especially with state of mental health and performance in academia with impact on later adult life activity.

Overstreet and Mathews (2011) discussed value from a public health model in provision of attention to prevent and reduce exposure to trauma impact and to also effectively manage and treat impact of trauma as it occurs. One of the problems noted was access to care, which could be supported within the context of school. The advantages from a public health model included (1) Continuum of coordinated services, (2) Participatory approach to establishment of cross-disciplinary collaboration, (3) Attention to key ecology of students such as present in the Ecological developmental model by Urie Brofenbrenner, and (4) Cultural sensitivity. Overstreet and Mathews indicated that employment of such an approach could facilitate improvements in both collective and individual performance of students, with personal growth such as improved self-regulation being a facet of that.

There is commonality of of early childhood traumatic experiences that foster life-long consequences (Holmes, Levy, Smith, Pinne, and Neese, 2015). Holmes, et al. described an initiative called Head Start Trauma Smart (HSTS) that grew out of collaboration between a local mental health provider and a local Head Start early childhood education program. Their initiative was founded on a trauma intervention model called Attachment, Self-Regulation, and Competency (SRC) because these were indicated by former research to be three core domains that were impacted by exposure to chronic interpersonal trauma. HSTS provided four components to facilitate decrease in impact from chronic trauma and promote development of longer-term resilience. These four components were.

(1) Training on the three domains of ARC to stakeholders such as parents and teachers in the lives of children.

(2) Intensive Individual Trauma-Focused Intervention for children referred for therapy on this impact.

(3) Classroom consultation to teachers and students.

(4) Peer-based mentoring with the staff and teachers.

Results indicated a need for intervention based in the collection of natural settings where children were such as home and school. Both teachers and parents indicated growth in their own awareness of the domains impacted from trauma and what these domains included in the life of an individual.

\section{Methodology of Study}

A study was conducted with students in academic preparatory programs for education such as teaching and school counseling with utilization of selected scales of the Motivated Strategies for Learning Questionnaire 
(MSLQ) (Taylor, 2012) - Organization, Resource Management, Effort regulation, and Help-Seeking. The purpose of the study was to assess facets of self-regulation for those educators who could best help prepare youth in development of self-regulation. As Grade Point Average (GPA) is a ready indicator of success in academic performance, the focus for the study was to examine correlation between student self-regulation in Organization, Resource Management, Effort regulation, and Help-Seeking and Grade Point Average (GPA). A survey was administered to 299 students (male and female) in both campus and online courses The survey included a self-report question for GPA to support confidentiality of participants. This survey was administered through Qualtrics and was anonymous with participants providing no personal identification.

\section{Results of Study on Self-regulation}

Organization. Organization factors include outlining of course materials to organize thoughts, identification of most important course ideas, and use of visual tools (charts, diagrams, and tables) to organize course material.

Outlining of course material to organize thoughts. The respondents were asked whether when they study for their courses they outline the material to assist them in organizing their thoughts. Around 33\% of the respondents strongly agreed. Secondly, around $40 \%$ of the respondents somewhat agreed. Thirdly, around $15 \%$ of the respondents indicated that they neither agreed nor disagreed, while around eight percent of the respondents indicated that they somewhat disagreed. Finally, around four percent of the respondents indicated that they strongly disagreed. Park (2003) revealed that a learning journal is very crucial. It has a high potential to not only increase a student's interest in course material, but also engagement. The learning journal also has a high potential to spur and empower students such that they are capable of taking responsibility for their own learning as well as becoming more reflective in their study (Park, 2003).

Identification of most important course ideas. The respondents were asked whether when studying for a course they go through readings and class notes to find the most important notes. While answering this question, around $59 \%$ of the respondents strongly agreed, while around $34 \%$ of the respondents somewhat agreed. The percentage of respondents who indicated they neither agreed nor disagreed is around five percent. Around one percent of the respondents somewhat disagreed, while around one percent strongly disagreed. Dunlosky, Rawson, Marsh, Nathan, \& Willingham (2013, pp. 1415) noted that students frequently have to learn high volumes of information. For this reason, students are necessitated to recognize what is crucial and the way various ideas link to each other. 
Use of visual tools to organize course material. The respondents were asked if they make simple charts, diagrams, or tables to assist them in organizing course material. About $14 \%$ of the respondents strongly agreed that they use the visual tools to organize course material, while around 33\% somewhat agreed. About $18 \%$ of the participants neither agreed nor disagreed. About $17 \%$ of the respondents somewhat disagreed that they make simple charts, diagrams, or tables to assist them in organizing course material. Finally, about $18 \%$ of the respondents strongly disagreed. According to Miller (2007), charts are important in conveying numeric patterns. They are the preferred way in conveying trends and relationships across and between data sets. Diagrams are important in presenting a visual description of a series of events, procedures or even physical characteristics. Tables are important in demonstrating numerous and exact text/numerical values in a small space. They are crucial in comparing and contrasting data values/characteristics/information among associated items or items with some shared features or variables (Miller, 2007).

Resource management. Resource management factors include favorable study environment, leveraging study time, regular place for studying, completion of assignments regularly, and planning for study time.

Favorable study environment. The respondents were asked if they study in a place where they can concentrate in their coursework. In answering this question, approximately 59\% of the respondents strongly agreed, while approximately $33 \%$ of the respondents somewhat agreed. Approximately five percent of the respondents neither agreed nor disagreed. Approximately two percent of the respondents somewhat disagreed, while approximately one percent of the participants strongly disagreed. According to Cannell (2007), a library is a suitable place for students to study.

Leveraging study time. The respondents were asked whether they make good use of their study time for courses. Around 39\% strongly agreed, while around $46 \%$ somewhat agreed. Around seven percent of the participants neither agreed nor disagreed. Around $7 \%$ of the participants somewhat disagreed, while one percent strongly disagreed. Similarly, Bembenutty (2009) and Ramdass \& Zimmerman (2011) noted that higher-achieving students in postsecondary institutions have a tendency to establish academic target goals, including making good use of their study time.

Regular place for studying. When asked if they have a regular place set aside for studying, about $38 \%$ of the respondents strongly agreed. About $39 \%$ of the respondents somewhat agreed. About eight percent of the respondents neither agreed nor disagreed. About nine percent of the participants somewhat disagreed, while about six percent strongly disagreed that they have a regular place set aside for studying. For Bryant, Matthews and Walton (2006), most students consider two factors when choosing a study 
location in a library: The first is physical environment. The second factor is low noise levels (Bryant et al.).

Completion of assignments regularly. The respondents were asked if they ensure they keep up with weekly assignments for courses. Around $77 \%$ of the respondents strongly agreed, while around $21 \%$ somewhat agreed. For the respondents who neither agreed nor disagreed, their percentage is around one. Around one percent of the respondents somewhat disagreed, while none of the respondents strongly disagreed. The findings counteracts the findings by Young (2002) who noted that professors have for a long time complained that students come to class not well prepared, without having finished their assignments.

Planning for study time. The respondents were asked if they schedule their life activities to give them enough time to study. About $34 \%$ of the respondents strongly agreed, while around $44 \%$ of the respondents somewhat agreed. The percentage of those respondents who neither agreed nor disagreed is around 12. About seven percent of the participants somewhat disagreed, while about three percent strongly disagreed. For Astin (1999), it is a good idea for students to plan for activities that improve the college learning experience when they are budgeting their time. A time diary can enable a student to figure out the relative importance of different activities (Astin).

Effort regulation. Effort regulation factors include striving to succeed in coursework, endurance in the context of monotonous course materials, and endurance when studying for classes in the context of boredom.

Striving to succeed in coursework. The respondents were asked if they work hard to do well in courses even if they do not like the course content/structure. About $79 \%$ of the respondents strongly agreed. About 19\% somewhat agreed, while about one percent neither agreed nor disagreed. About one percent of the participants somewhat disagreed, while none of the participants strongly disagreed that they work hard to do well in courses even if they do not like the course content/structure. Bir and Myrick (2015) recommend the use of summer bridge programs in postsecondary institutions that serves many objectives. One such is assisting in easing the transition from high school education to a postsecondary education. Secondly, the programs impart self-efficacy, resilience, as well as confidence among students. Students are afforded the chance to take classes/courses in academic strategies, including writing. Such courses usually do not bear academic credit. The students focus on a weaker academic area and also get the chance to concentrate on skills such as organizational skills (Bir and Myrick).

Endurance in the context of monotonous course materials. The respondents were asked if they manage to keep working until they finish a course, although the course materials are dull as well as uninteresting. Around $72 \%$ of the respondents strongly agreed. Secondly, around $25 \%$ somewhat 
agreed. Thirdly, around one percent neither agreed nor disagreed. Fourthly, around one percent of the respondents somewhat disagreed. Finally, around one percent strongly disagreed. The finding aligns with Bauerlein (2013) recommendation of how students should overcome dull and uninteresting course materials. In this context, students should work through boredom on their own, which is a matter of stamina rather than intellect.

Endurance when studying for classes in the context of boredom or laziness. The respondents were asked if they abide by a plan they created for studying for classes in the context of boredom or when they feel lazy. Approximately $61 \%$ of the respondents strongly agreed, while approximately $32 \%$ somewhat agreed. The percentage of respondents who indicated they neither agreed nor disagreed is around four. Moreover, approximately two percent of the respondents somewhat disagreed, while approximately one percent strongly disagreed. In comparison, Park (2008) established that students who are high procrastinators often indicated they were lazy. In other words, the students were not good at following their plans in addition to intentions. Ordinarily, the procrastinators planned to work in advance. Though, they ended up doing in the last minute because they took part in other events not in their plan (Park).

\section{Academic Performance}

Letter Grade Average. The respondents were asked about their letter grade average in their respective courses at the moment. About $80 \%$ of the respondents stated that they have an A average. About $15 \%$ of the respondents stated they have a B average, while about four percent stated they have a $\mathrm{C}$ average. About one percent of the respondents indicated they have a D average, while none stated they have an $\mathrm{F}$ average.

Numerical Grade Point Average (GPA). The respondents were asked about their numerical Grade Point Average (GPA) in their courses at the moment. About $47 \%$ of the respondents stated their GPA is 4.00 . Forty three (43) percent of the respondents indicated they have a GPA of 3.00-3.99. About eight percent of the respondents stated they have a GPA of 2.00-2.99. About one percent of the respondents stated they have a GPA of 1.00-1.99. Finally, about one percent of the respondents stated they have a GPA of less than one percent.

\section{Hypotheses Testing}

$H 1_{a}$ : There is a positive correlation between student self-regulation (organization, use of visual tools) and Grade Point Average (GPA).

A weak positive correlation was found between self-regulation (organization, use of visual tools to organize course material) and Grade Point Average (GPA) $(\mathrm{r}=0.3459 ; \mathrm{p}=0.2843)$. In other words, the more the 
respondents use visual tools to organize course materials, the more they earn better grades and consequently a superior GPA. Though, the weak positive correlation suggests that the use visual tools alone cannot contribute to a superior GPA. Other self-regulation factors are critical in realizing a superior GPA. The hypothesis was accepted.

H1 $1_{b}$ : There is a positive correlation between student self-regulation (resource management, leveraging study time) and Grade Point Average (GPA).

A very strong positive correlation was found between self-regulation (resource management, leveraging study time) and GPA average $(r=0.9721$; $\mathrm{p}=0.0028$ ). In other words, a student who makes good use of their study time has a high potential of scoring a high GPA. The hypothesis was accepted.

\section{H1 : There is a positive correlation between student self-regulation (effort regulation, endurance when studying for classes in the context of boredom) and Grade Point Average (GPA).}

A very strong positive was found between self-regulation (effort regulation, endurance when studying for classes in the context of boredom) and GPA average $(\mathrm{r}=0.9425 ; \mathrm{p}=0.0082)$. In other words, a student who works hard in the context of boredom has a high likelihood of scoring a high GPA. The hypothesis was accepted.

\section{Discussion}

The study investigated several student self-regulation factors. Study results provide implications for development of self-regulation in youth through efforts by educators. Following is discussion of those results and accompanying implications for application to building resilience for management of chronic trauma.

One factor is Organization. One Organization sub-factor is outlining of course material to organize thoughts. Around 73\% (33\% highly and 40\% fairly) of the respondents indicated they outline course material to organize thoughts. One key tool that students could use to organize thoughts is a learning journal. This practice of thought organization would facilitate reflection and planning on effective life management.

A second Organization sub-factor is identification of most important course ideas. The study revealed that around 93\% (59\% highly and 34\% fairly) of respondents agreed that they identify most important course ideas through development of summaries. Successful summaries recognize key points of lessons or general facets of life.These methods appeal to students since the methods are simple to use (Dunlosky et al., p. 18). 
A third Organization sub-factor is use of visual tools to organize course material. The study revealed that only about $47 \%$ (14\% highly and $33 \%$ fairly) of the respondents use visual tools (charts, diagrams, and/or tables) to organize course material. The current study emphasizes that charts are important in conveying numeric patterns. They are the preferred way in conveying trends and relationships across and between data sets. Diagrams are important in presenting a visual description of a series of events, procedures or even physical characteristics. Tables are important in demonstrating numerous and exact text/numerical values in a small space. They are crucial in comparing and contrasting data values, characteristics, and information among associated items or items with some shared features or variables (Miller, 2007). Practice in comparison and contrast of data can be taught at all levels of school to support development of positive decision making capacity.

A second self-regulation factor that the current study investigated is Resource Management. One sub-factor of this factor is Favorable Study Environment. The majority of the students (92\%--59\% strongly agreed and $33 \%$ somewhat agreed) have a favorable study environment. The current study recognizes a library as a convenient place for students to not only study coursework, but also perform research. The application from this in building self-regulation that promotes resilience for trauma impact is awareness of what is or is not favorable as an environment of support and then action to provide favorable support environments for self.

A second Resource Management sub-factor is leveraging study time. The current study revealed that around 85\% (39\% highly and 46\% fairly) make good use of their study time. Application from this for resilience building for chronic trauma is approximating the amount of time a task needs and practice of good time management. Examples of such habits are avoiding too much on an activity at one time, planning particular times for activities, and avoiding/eliminating lifestyle distractions. More examples are establishing particular goals for their time usage as well as examining their progress (Bembenutty, 2009; Ramdass \& Zimmerman, 2011).

A third Resources Management sub-factor is a regular place for studying. The current study revealed that around $77 \%$ (38\% strongly agreed and 39\% somewhat agreed) of students have a regular place for studying. Regularity in structuring a student's daily life can help build resilience in that habitual structure can provide an anchor of something normal in the midst of trauma.

A fourth Resources Management sub-factor is planning for study time. The study revealed that a significant percentage of students (around 78\%-$34 \%$ strongly agreed and $44 \%$ somewhat agreed) schedule their life activities to give them enough time to study. It is recommended that students should always aim to develop processes of self-regulated learning. An example of 
such processes is establishing goals. More examples of processes of selfregulated learning are participating in strategic planning, monitoring performance and reflecting. These processes are important for students who are independently balancing their learning with life activities (Huie, Winsler, \& Kitsantas, 2014). Students should always have a tendency to spend equal time in both academics as well as leisure to ensure they have superior cumulative Grade Point Averages (GPAs) (Brint and Cantwell, 2010). This also promotes stronger resilience throughout life.

A third self-regulation factor that the current study investigated is Effort Regulation. One Effort Regulation sub-factor is striving to succeed in coursework. The study revealed that most respondents (around 98\%--79\% strongly agreed and 19\% somewhat agreed) strive to succeed in coursework even if they do not like the course content/structure. This striving to succeed in learning or other life endeavors builds a habit of pushing through adversive life experiences such as chronic trauma.

A second Effort Regulation sub-factor is endurance in the context of monotonous course materials. The course revealed that most respondents (about $97 \%--72 \%$ strongly agreed and $21 \%$ somewhat agreed) manage to keep working until they finish a course, although the course materials are dull as well as uninteresting. Chronic trauma has a time-frame of no predictable end time and endurance is needed to develop and maintain as high a quality of life possible amidst the ongoing traua.

A third similar Effort Regulation sub-factor is endurance when studying for classes in the context of boredom/laziness. The study revealed that most respondents (about 93\%--61\% strongly agreed and 32\% somewhat agreed) abide by a plan they created for studying for classes in the context of boredom or when they feel lazy. The more a student fails to pay attention to their boredom, the more it will be easier for them to grasp key concepts and consequently pass a specific course (Bauerlein, 2013). This practice helps to build resilience for surviving and thriving despite trauma as it strengthens capacity to focus on attaining the positive.

\section{Conclusion}

Self-regulation is a life skill that benefits human development in general and can support building of resilience with which to survive and thrive through experiences of trauma, especially when impact of trauma has a chronic nature. A study conducted with educators in training provided indication that educators are enriched to help students grow in self-regulation as the educators themselves practice facets of self-regulation. Academic study provides an experience that requires exercise of self-regulation to attain success much as a need to survive and thrive through trauma. Facets of selfregulation that educators can promote with their students are Organization 
skills such as work in organization of thought such as with outlining of material and Increased Resource Management such as availing selves of a school library or attention to student time management. The third area that educators can help students with is Effort Regulation, which might require more focus on inner student development such as increased desire to succeed and capacity for endurance in the face of perceived lack of interest in required subject matter. Results from this study can guide educators in those facets of self-regulation to promote with students to support building habitual resilience as a support for living through and past chronic trauma. More research is needed in educator interventions to enhance student internal selfexpectations for success and will to endure life challenges and expectations that might be uninteresting, yet needful for life success.

\section{References:}

1. Astin, A. W. (1999). Student involvement: A developmental theory for higher education. Journal of College Student Development, 40, 518529.

2. Bauerlein, M. (2013). Boredom in class. Retrieved from Retrieved from Education Next website: https://www.educationnext.org/boredom-in-class/

3. Bembenutty, H. (2009). Academic delay of gratification, self-efficacy, and time-management among academically unprepared college students. Psychological Reports, 104, 612-623. doi:10.2466/pr0.104.2.613-623

4. Bir, B. \& Myrick, M. (2015). Summer bridge's effects on college student success. Journal of Developmental Education, 39(1), 22-30. Retrieved from https://files.eric.ed.gov/fulltext/EJ1106091.pdf

5. Brint, S., \& Cantwell, A. M. (2010). Undergraduate time use and academic outcomes: Results from the University of California Undergraduate Experience Survey 2006. Teachers College Record, 112, 2441-2470.

6. Bryant, J. Matthews, G. and Walton, G. (2009). Academic libraries and social and learning space: A case study of Loughborough University Library, UK. Journal of Librarianship \& Information Science, 41(1): 7-18.

7. Cannell, S. (2007).The changing research environment: Implications for library space. SCONUL Focus, 40, 43-46.

8. Dunlosky, J., Rawson, K. A., Marsh, E. J., Nathan, M. J., \& Willingham, D. T.(2013). Improving students' learning with effective learning techniques: promising directions from cognitive and educational psychology. Psychological Science in the Public Interest, 14(1), 4-58. doi:10.1177/1529100612453266 
9. Gilgun, J. F. \& Hirschey, S. (2017). A four-factor model for family case management services with children and families who have experienced complex trauma. Journal of Family Theory \& Review. 9, 537-556.

10. Holmes, C, Levy, M, Smith, A. Pinne, S. \& Neese, P. (2015). A model for creating a supportive trauma-informed culture for children in preschool settings. Journal of Child and Family Studies, 24,1650-1659.

11. Jacobson, R.R. \& Harris, S.M. (2008). Does the type of campus influence self-regulated learning as measured by the motivated strategies for learning questionnaire (MSLQ)? Education, 128 (3), 412 -431 .

12. Marr, J. \& Wilcox, S. (2015). Self efficacy and social support mediate the relationship between internal health locus of control and health behaviors in college students. Journal of Health Education, 46(3), 122131.

13. Overstreet, S. \& Mathews, T. (2011). Challenges association with exposure to chronic trauma: Using a public health framework to foster resilient outcomes among youth. Psychology in the Schools, 48(7), 738-754.

14. Park, C. (2003). Engaging students in the learning process: The learning journal. Journal of Geography in Higher Education, 27 (2), 183-199.

15. Park, S. W. (2008). Self-regulation of academic procrastinators: A mixed methods study (Unpublished master's thesis). The Pennsylvania State University, Pennsylvania, United States.

16. Potgieter, S. (2015). Wellness as a virtue in Health Sciences students: Are they practising what they preach? South African Journal of Clinical Nutrition, 28(4), 152-153.

17. Ramdass, D., \& Zimmerman, B. J. (2011). Developing self-regulation skills: The important role of homework. Journal of Advanced Academics, 22, 194-218. doi:10.1177/19322 02x1102200202

18. Ryan, K., Lane, S.J. \& Powers, D. (2017). A multidisciplinary model for treating complex trauma in early childhood. International Journal of Play Therapy. 26(2), 111-123.

19. Swick, K. J., Knopf, H, Williams, R. \& Fields, M.E. (2013). Familyschool strategies for responding to the needs of children experiencing chronic stress. Early Childhood Education Journal, 41, 181-186.

20. Taylor, R. T. (2012). Review of the Motivated Strategies for Learning Questionnaire (MLSQ) using reliability generalization

21. techniques to assess scale reliability (Doctoral dissertation). Retrieved from ERIC (ED546666). Auburn University, Auburn, AL. 
22. Vermunt, J.D. (2005). Relations between student learning patterns and personal and contextual factors and academic performance. Higher Education, 49, 205-234.

23. Young, J. R. (2002). Homework? What homework? Chronicle of Higher Education, 9(15), p. A35 